\title{
To breathe or not to breathe: That is the question
}

\author{
Stephen R. Hazelrigg, MD
}

\author{
From the Division of Cardiothoracic Surgery, SIU School of Medicine, Springfield, Ill. \\ Disclosures: Author has nothing to disclose with regard to commercial support. \\ Received for publication April 7, 2017; accepted for publication April 12, 2017; available ahead of print June 7 , \\ 2017. \\ Address for reprints: Stephen R. Hazelrigg, MD, Division of Cardiothoracic Surgery, SIU School of Medicine, \\ 701 N 1st St, Suite D252, P.O. Box 19679, Springfield, IL 62702 (E-mail: shazelrigg@ siumed.edu). \\ J Thorac Cardiovasc Surg 2017; 154:e33 \\ $0022-5223 / \$ 36.00$ \\ Copyright (C 2017 by The American Association for Thoracic Surgery \\ http://dx.doi.org/10.1016/j.jtcvs.2017.04.044
}

This case report by Kocher and colleagues ${ }^{1}$ describes a successful resection of a metastatic lung lesion in a patient who had previously undergone a pneumonectomy. Although cases requiring lung resection after pneumonectomy are infrequent, they always require careful thought and planning: thought with regard to appropriate surgical indications, and planning with regard to the conduct of the operation. The main operative issues are (1) how to ventilate the patient while providing adequate exposure when doing the lung resection and (2) how to minimize postoperative respiratory complications.

One option is to use a standard open (thoracotomy) approach, with intermittent short periods of discontinuation of ventilation. This works well but can be an issue with less than ideal exposure, and with the required rib spreading it certainly adds to the postoperative pain, which can increase the risk of pulmonary complications. All other options include some method of extracorporeal oxygenation with either cardiopulmonary bypass or with extracorporeal membrane oxygenation (usually venovenous). Extracorporeal membrane oxygenation has been used in the past, but Kocher and colleagues ${ }^{1}$ used a newer single cannula that allows oxygenation to occur. With this technique, the lung can be deflated to allow a thoracoscopic lung resection. In this way, they attempted to reduce postoperative pain and thus limit complications.

Kocher and colleagues ${ }^{1}$ chose to use a uniportal approach for their minimally invasive lung resection. They are a proponent of this approach, which is gaining some recent support. It should be noted, however, that there really are no data to support the contention that this uniportal approach

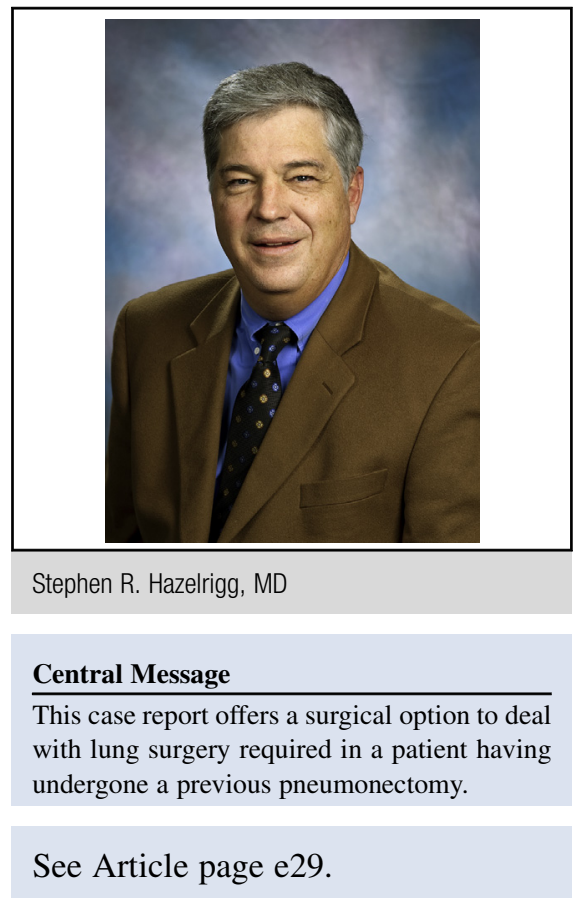

is superior to a more traditional video-assisted thoracoscopic surgical approach with 3 small ports. Both thoracoscopic approaches achieve the goal of reducing postoperative pain in the hope of minimizing respiratory complications. Similarly, on the basis of available data, one can question their decision to place an epidural catheter when video-assisted thoracoscopic surgical technique is used, although I understand their logic.

In the end, the case report offers a viable method of management in this rare but demanding patient population. Kocher and colleagues ${ }^{1}$ are to be congratulated for their innovative approach and successful short-term outcome.

\section{Reference}

1. Kocher GJ, Zehnder A, Erdoes G, Seidl C, Winkler B, Schmid RA Single-cannula, single-incision thoracoscopic anatomic segmentectomy after pneumonectomy. J Thorac Cardiovasc Surg. 2017;154:e29-31. 